\title{
Estrogen depletion alters mineralization regulation mechanisms in an ovariectomized monkey animal model
}

\author{
E.P. Paschalis ${ }^{1}$, S. Gamsjaeger ${ }^{1}$, K. Condon $^{2}$, K. Klaushofer ${ }^{1}$, D. Burr ${ }^{2}$
}

${ }^{1}$ Ludwig Boltzmann Institute of Osteology at the Hanusch Hospital of WGKK and AUVA Trauma Centre Meidling, 1st Medical Department, Hanusch Hospital, Heinrich Collin Str. 30, A-1140 Vienna, Austria

2 Department of Anatomy and Cell Biology, Indiana University School of Medicine, Indianapolis, IN 46202, USA; Department of Biomedical Engineering, Indiana UniversityPurdue University, Indianapolis (IUPUI), Indianapolis, IN 46202, USA

Correspondence to: Eleftherios P. Paschalis

Ludwig Boltzmann Institute of Osteology

Hausch Krankenhaus

Heinrich Collin Str. 30

A-1140, Vienna

Austria

Eleftherios.paschalis@osteologie.at

This is the author's manuscript of the article published in final edited form as:

Paschalis, E. P., Gamsjaeger, S., Condon, K., Klaushofer, K., \& Burr, D. (2018). Estrogen depletion alters mineralization regulation mechanisms in an ovariectomized monkey animal model. Bone. https://doi.org/10.1016/j.bone.2018.11.004 


\section{Abstract}

Ovariectomized animal models have been extensively used in osteoporosis research due to the resulting loss of bone mass. The purpose of the present study was to test the hypothesis that estrogen depletion alters mineralization regulation mechanisms in an ovariectomized monkey animal model. To achieve this we used Raman microspectroscopy to analyze humeri from monkeys that were either SHAM-operated or ovariectomized ( $\mathrm{N}=10$ for each group). Measurements were made as a function of tissue age and cortical surface (periosteal, osteonal, endosteal) based on the presence of calcein fluorescent double labels.

In the present work we focused on osteoid seams (defined as a surface with evident calcein labels, $1 \mu \mathrm{m}$ distance away from the mineralizing front, and for which the Raman spectra showed the presence of organic matrix but not mineral), as well as the youngest mineralized tissue between the second fluorescent label and the mineralizing front, $1 \mu \mathrm{m}$ inwards from the front with the phosphate mineral peak evident in the Raman spectra (TA1). The spectroscopically determined parameters of interest were the relative glycosaminoglycan (GAG) and pyridinoline (Pyd) contents in the osteoid, and the mineral content in TA1.

At all three cortical surfaces, significant correlations were evident in the SHAM-operated animals between osteoid GAG (negative) and Pyd content, and mineral content, unlike the OVX animals.

These results suggest that in addition to the well-established effects on turnover rates and bone mass, estrogen depletion alters the regulation of mineralization by GAGs and Pyd.

Keywords: Estrogen, glycosaminoglycans, pyridinoline, Raman spectroscopy, bone formation, osteoporosis 


\section{Introduction}

Estrogen is the most important systemic regulator of bone metabolism in both women and men [1-3]. It controls skeletal homeostasis through effects on all three bone cell types (osteoblasts, osteoclasts, and osteocytes) [2], differentially in the four skeletal envelopes [4, 5]. Estrogen depletion results in increased bone resorption coupled with an increase in global bone formation [6], the former in a greater magnitude thus resulting in a net bone loss. It increases osteocyte apoptosis [7-9], resulting in greater bone remodeling and resorption. Estrogen depletion is thought to directly affect the osteoblast through increases in apoptosis, oxidative stress, and NF- $\kappa \mathrm{B}$ activity [2], and is also suspected to decrease sclerostin [10]. Moreover, the effects of estrogen depletion are bone envelope-specific $[5,11,12]$.

Several animal models have been used in the study of postmenopausal osteoporosis. While the ovariectomized rat model is the most extensively used due to the low cost and ease of animal handling [13], it lacks the Haversian canal system present in human cortical bone. Moreover, ovariectomy does not significantly change cortical thickness as endosteal resorption is balanced by periosteal formation [13]. Nonhuman primates (monkeys) are not limited by any of these drawbacks, are genetically close to humans, have menstrual cycles and a menopause, and their immune system is comparable to humans; even though menopause occurs much later chronologically compared to humans, this can be compensated for through ovariectomy [13]. Their bones are characterized by increased turnover rates, osteopenia, and significant decreases in elastic modulus, shear modulus, failure shear stress, and failure torque $[14,15]$.

It is generally accepted that biological fluids are supersaturated with respect to apatites (the chemical phase of bone mineral), and mineralization is strictly regulated through appropriate inhibitors and nucleators that determine when, where, and how many mineral 
crystallites will be formed. The purpose of the present study was to test the hypothesis that estrogen depletion alters this biological regulation of mineralization. We used Raman microspectroscopic analysis (affording spatial resolution of $\sim 1 \mu \mathrm{m}$ ) to investigate organic matrix quality (in particular glycosaminoglycan and pyridinoline content) in the osteoid (defined as a surface with evident calcein labels, $1 \mu \mathrm{m}$ distance from the mineralizing front, and for which the Raman spectra showed the presence of organic matrix but not mineral) and its correlation to the amount of freshly deposited mineral (surfaces with evident calcein labels, between the mineralizing front and the second label) in humeri from monkeys that were either SHAM-operated (SHAM) or ovariectomized (OVX).

Identifying differences in the correlation between osteoid organic matrix quality and freshly deposited mineral content could further our understanding of how estrogen controls bone formation and mineralization.

\section{Materials \& Methods}

\section{Animals}

Details of the animals from which bone tissue was analyzed for the present study have been published previously [16]. All procedures were approved by the Animal Care and Use Committee of the Bowman Gray School of Medicine at Wake Forest University and conformed to institutional and NIH guidelines. In summary, natural habitat-derived adult (9 years of age and weighing $2.77 \pm 0.03 \mathrm{~kg}$ ) female cynomolgus monkeys (Macaca fascicularis) were imported from Indonesia and quarantined for 3 months. Monkeys were screened radiographically to ensure absence of open growth plates and skeletal abnormalities. Double fluorochrome labels were given at 6 months (tetracycline $\mathrm{HCl}, 25 \mathrm{mg} / \mathrm{kg}$, intravenously [iv]), 15 months (alizarin complexone, $20 \mathrm{mg} / \mathrm{kg}$, iv), and before death at 18 months (calcein, $10 \mathrm{mg} / \mathrm{kg}$, iv) using a 1-12-1 schedule, with death 7 days after 
administration of the final label [16]. In the present study, bone from SHAM-operated animals (SHAM; N=10) was examined and compared to bone from ovariectomized (OVX; $\mathrm{N}$ $=10)$ animals. Attention was focused on the calcein labels as they identify areas of the most recent bone formation (Fig. 1).

\section{$\underline{\text { Anatomical area selection criteria }}$}

The following areas were analyzed at periosteal, osteonal, and endosteal surfaces with calcein fluorescent labels evident:

a) Osteoid: defined as a surface with evident calcein labels, $1 \mu \mathrm{m}$ distance from the mineralizing front, and for which the Raman spectra showed the presence of organic matrix but not mineral.

b) Youngest mineralized tissue (TA1): surfaces with evident calcein labels, between the mineralizing front and the second label.

For each animal, nine different measurements were made at each of the areas outlined above, and averaged to create a single statistical data point.

\section{$\underline{\text { Raman analysis }}$}

Raman microspectroscopic analyses employed a Senterra (Bruker Optik GmbH) instrument. A continuous laser beam was focused onto the sample through a Raman fluorescence microscope (Olympus BX51, objective 50x) with an excitation of $785 \mathrm{~nm}$ (100 $\mathrm{mW}$ ) and a lateral resolution of $\sim 0.6 \mu \mathrm{m}$. The Raman spectra were acquired from the bone surface, using a thermo-electric-cooled charge-coupled device (CCD) (Bruker Optik GmbH). All data analysis was done with the Opus Ident software package (OPUS 6.5, Bruker Optik $\mathrm{GmbH}$ ). Once acquired, the Raman spectra were baseline corrected (rubber band, 5 iterations) to account for fluorescence. The interlabel distance (IrLD) of the calcein double 
labels was calculated from the fluorescence images obtained through the Raman microscope. Based on the acquired Raman spectra, the following parameters were calculated:

I. The organic matrix content in the osteoid seam (osteoid consists of organic matrix and water) and at TA1 based on the ratio of integrated area of the Amide III (1215-1300 $\mathrm{cm}^{-1}$ ) band to the spectral slice 494-509 $\mathrm{cm}^{-1}$ representative of PMMA [17].

II. The mineral content at the youngest tissue age (TA1), between the second calcein label and the mineral front, based on the ratio of the integrated area of the ${ }_{2} \mathrm{PO}_{4}$ (410-460 $\mathrm{cm}^{-1}$ ) band to the spectral slice $494-509 \mathrm{~cm}^{-1}$ representative of PMMA.

III. The mineral maturity / crystallinity (MMC) was calculated from the inverse of the full width at half height $v_{1} \mathrm{PO}_{4}$ peak [18].

IV. The relative glycosaminoglycans (GAG) content was calculated from the ratio of the integrated areas of the $\mathrm{CH}_{3} \quad\left(1365-1390 \mathrm{~cm}^{-1}\right)$ band representative of glycosaminoglycans [19], to the amide III $\left(1215-1300 \mathrm{~cm}^{-1}\right)$ band. In Raman spectroscopy, the spectral signature of proteoglycans is due to GAG chains.

V. The relative pyridinoline content, calculated from the ratio of the Raman intensity at $1660 \mathrm{~cm}^{-1} /$ the integrated area of the Amide I band $\left(\sim 1620-1700 \mathrm{~cm}^{-1}\right)[20,21]$.

\section{$\underline{\text { Statistical analysis }}$}

Data are presented as mean and SD, or mean (where correlation analysis is involved). Between groups comparisons were made by unpaired t-tests. Significance was assigned to $\mathrm{p}<0.05$. For visualization purposes, where individual data are shown, regression lines (either linear or exponential growth/decay) are also plotted, although comparisons are not based on any regression analysis. 


\section{Results}

Figure 1 shows an overview picture from a thin section of a SHAM monkey humerus showing all 3 fluorescent labels that were administered to the animals (a). For the purposes of the present study only osteons with evident calcein labels were considered (b). Fig. 1c shows three Raman spectra acquired in the area of TA1 (solid black line), osteoid (dashed black line), and PMMA away from the bone tissue (red dashed line). The peaks used in the present analysis have been labeled. As may be seen, the presence or absence of Amide I discriminates between areas of just PMMA and PMMA-embedded bone tissue. The presence of Amide I and Amide III coupled with the presence or absence of the $v_{2} \mathrm{PO}_{4}$ peak allows the discrimination between osteoid and mineralized bone tissue.

The advancement of the mineralizing front was faster in the OVX animals as suggested by the significantly greater interlabel distance compared to SHAM at osteonal $(+35 \%, \mathrm{p}<0.05)$ and endosteal $(+236 \%, \mathrm{p}<0.05)$ forming surfaces but not at periosteal ones (Fig. 2).

No differences in organic matrix content between SHAM and OVX animals in either the osteoid or at TA1 were evident (Fig 3) at any of the three cortical surfaces (periosteal, osteonal, endosteal). The amount of mineral in the most newly formed bone (TA1) was also similar between the two animal groups (Fig 4, top row) at all cortical surfaces considered. We previously published that the GAG and Pyd content is not affected by estrogen depletion in either osteoid seam or at the youngest mineralized tissue [5]. The mineral maturity / crystallinity at TA1 was likewise statistically similar between SHAM and OVX animals (Fig. 4, bottom row).

When the osteoid seam GAG content was considered against the mineral content at TA1 (Fig. 5, top row), there was a significant negative correlation at periosteal $(\mathrm{r}=-0.65, \mathrm{p}=$ 
$0.04)$, osteonal $(\mathrm{r}=-0.83, \mathrm{p}=0.005)$, and endosteal $(\mathrm{r}=-0.88, \mathrm{p}=0.001)$ surfaces in the SHAM animals, which was not evident in the OVX ones (periosteal $\mathrm{r}=-0.04, \mathrm{p}=0.9$; osteonal $\mathrm{r}=-0.1, \mathrm{p}=0.79$; endosteal $\mathrm{r}=-0.56, \mathrm{p}=0.09)$.

When the osteoid seam Pyd content was considered against the mineral content at TA1 (Fig. 5, bottom row), there was a significant positive correlation at periosteal $(r=0.87, p$ $=0.0009)$, osteonal $(r=0.87, p=0.002)$, and endosteal $(r=0.75, p=0.02)$ surfaces in the SHAM animals, which was not evident in the OVX ones (periosteal $r=0.34, p=0.36$; osteonal $\mathrm{r}=-0.072, \mathrm{p}=0.84$; endosteal $\mathrm{r}=0.03, \mathrm{p}=0.93$ ).

\section{Discussion}

Bone formation rate is not a singular entity but it encompasses rates of several concomitant yet partly independent from each other processes. These include the rate of osteoblast differentiation, the rate of volumetric expansion, the rate of organic matrix synthesis per osteoblast (determining the density of the organic matrix in the newly created bone volume), the rate of organic matrix maturation (involving posttranslational modifications of proteins such as phosphorylation or dephosphorylation, collagen posttranslational modifications, addition or subtraction of proteoglycan GAG chains amongst others), the rate of mineral nucleation (formation of mineral nuclei in the organic matrix scaffold), the rate of mineral maturation (chemical transformation of the early mineral nuclei), and rate of mineral accumulation (how fast additional mineral is accumulated onto the initial mineral nuclei). Not all of these rates are straight forward to measure in a biological system such as bone.

Mineral apposition rate (MAR), measuring the average distance between two fluorescent labels administered at different times is commonly used to provide a measure of individual osteoblastic activity, and describe the rate of advancement of the mineralizing 
front within a defined period. In the present study, the interlabel distance was significantly higher in the OVX animals compared to SHAM at osteonal and endosteal but not periosteal surfaces. This difference between cortical surfaces would be in agreement with previously published data on these animals highlighting the uniqueness of the periosteal surface (undergoing modeling) compared to osteonal and endosteal ones (undergoing remodeling) [5], although the contribution of the animal age (these animals are adult ones) and the possible decline in modeling rates can neither be excluded nor quantified in the present experiments.

Raman microspectroscopy as employed in the present study analyzes a micro-volume of $\sim 1 \mathrm{x} 1 \mathrm{x} 1 \mu \mathrm{m}^{3}$. As such, the microvolumetric density of the organic matrix (organic matrix content within the micro-volume considered) in the osteoid seam as well as in the earliest deposited mineralized tissue (TA1) is similar in the SHAM and OVX animals, and the same holds for the mineral content at TA1. These results suggest that estrogen depletion does not alter the microvolumetric density of organic matrix in either the osteoid seam or the newly mineralized tissue, or the mineral in the newly mineralized tissue, but alters the rate of mineralization (based on IrLD). The lack of differences in mineral content between the animal groups at the youngest mineralized tissue employing the metric of mineral content normalized for PMMA content is in agreement with previously published results based on the more widely used metric of mineral / matrix ratio which led to the conclusion that ovarian hormone depletion does not affect the initial amount of mineral formed, but rather decelerates the rate of subsequent mineral accumulation [5]. The reason that we used the mineral/PMMA rather than the mineral / matrix ratio in the present work is that even though results are the same with both methods of expressing mineral content, the latter is sometimes confusing to the general readership as an increase in mineral / matrix ratio may be interpreted in several different ways. For example, in a previous study analyzing paired iliac crest biopsies from 
healthy females before and immediately following menopause, the mineral / matrix ratio was increased post-menopause, not because there was an increase in mineral content but rather a decrease in organic matrix content, an observation consistent with previously published biochemical data [20]. With the exception of thermogravimetric analysis which directly and unequivocally measures mineral and organic matrix contents, all other analytical techniques measuring mineral content based on a surrogate (either calcium, or phosphate, or hydroxyl, or carbonate) thus are subject to potential contribution from the variable stoichiometry of bone apatite crystallites (biologically relevant apatites are highly substituted) which is dependent on age, tissue age, and health status. Raman spectroscopic analysis has minimal interference if any at all from the variability in the apatite stoichiometry as the same spectrum includes semi-quantitative information of the apatite crystallite stoichiometry in the mineral maturity / crystallinity metric $[22,23]$. In the present study no significant differences existed between SHAM-operated and ovariectomized animals, further supporting the suggestion that the mineral content as measured in the present study has minimal if any contribution from variable mineral stoichiometry.

Glycosaminoglycans are part of proteoglycans, and are responsible for the characteristic Raman band at $\sim\left(1365-1390 \mathrm{~cm}^{-1}\right)$ [19]. Even though it is not possible to identify individual proteoglycans by Raman analysis, one needs to bear in mind that in the major proteoglycans in bone - biglycan and decorin -chondroitin 4-sulfate constitutes about $90 \%$ of the total GAG contentare [24]. Proteoglycans are known negative modulators of mineralization and bone turnover, and are present in micro- and nano-porous spaces such as osteocyte lacunae and canaliculi ensuring that these spaces remain mineral-free (the major proteoglycan present in these spaces is perlecan) [25-31]. Pyridinoline is a major enzymatic trivalent mineralizing type I collagen cross-link [32]. Enzymatic cross-links provide the fibrillar matrices with mechanical properties such as tensile strength and viscoelasticity [32, 
33], and are important determinants of bone strength [34-37]. Mineralization of the collagen scaffold is dependent on fibril structure and organization, and it has been reported that the ratio of pyridinoline / deoxypyridinoline is associated with mineralization amount [38]. In the present work, there were significant correlations between the osteoid GAG (negative) and Pyd (positive) contents and the mineral content in the newly mineralized tissue in the SHAM group, which would be in general agreement with what is published in the literature concerning the relationship of these two organic matrix attributes and mineralization. On the other hand, there was no such correlation observed in the OVX group, even though there were no differences in GAG and Pyd content between SHAM and OVX animals, suggesting that the mechanism of regulation of mineral nucleation and accumulation by these two organic matrix characteristics is altered upon estrogen depletion, even though there were no differences in mineral content in the newly mineralized tissue between the two groups despite more rapid bone mineralization in OVX.

The results of the present study show a significant correlation between osteoid seam GAG and Pyd content in recently formed bone in the SHAM but not the OVX animals. This observation holds at all three cortical surfaces. These results suggest that estrogen depletion alters the regulation of bone mineralization.

Conflict of interest: None of the authors declares any

Acknowledgements: The present study was supported by the Allgemeine Unfallversicherungsanstalt (AUVA), research funds of the Austrian workers compensation board, and the Wiener Gebietskrankenkasse (WGKK), Viennese sickness insurance funds. It was also supported in part by Eli Lilly \& Co. 


\section{Figure Legends}

Figure 1: Overview of a humerus bone cross-section from a SHAM-operated animal (a) showing the calcein double labels amongst others; an osteon with calcein double labels evident (b). The osteoid seam was defined as a surface with evident calcein labels, $1 \mu \mathrm{m}$ distance from the mineralizing front, and for which the Raman spectra showed the presence of organic matrix but not mineral, while TA1 representing the youngest mineralized tissue was located at surfaces with evident calcein labels, between the mineralizing front and the second label. Typical Raman spectra obtained in the osteoid seam (dashed line) and at TA1 (solid line) are shown in Fig. 1c, along with a spectrum obtained in an area of PMMA and devoid of any bone tissue, with the peaks of interest labeled.

Figure 2: Interlabel distance (mean and SD) comparison between SHAM and OVX animals at the three different cortical surfaces. OVX animals exhibited significantly greater values at osteonal $(+35 \%, \mathrm{p}<0.05)$ and endosteal $(+236 \%, \mathrm{p}<0.05)$ surfaces, unlike periosteal ones.

Figure 3: Organic matrix content in the osteoid seam (top row) and in the youngest mineralized tissue (bottom row) at the three different cortical surfaces. There were no differences between the SHAM-operated and the OVX animals.

Figure 4: Mineral content in the youngest mineralized tissue (between the second calcein fluorescent label and the mineralizing front) at the three different cortical surfaces (top row). There were no differences between the SHAM-operated and the OVX animals. Similarly, no 
significant differences between the two animal groups in mineral maturity / crystallinity were evident (bottom row).

Figure 5: Top row: correlations between osteoid GAG and youngest mineral content at the three cortical surfaces. Significant negative correlations were evident in the SHAM animals at all three (periosteal $r=-0.65, p=0.04$; osteonal $r=-0.83, p=0.005$; endosteal $r=-0.88, p$ $=0.001)$, unlike the OVX ones. Bottom row: correlations between osteoid Pyd and youngest mineral content at the three cortical surfaces. Significant correlations were evident in the SHAM animals at all three (periosteal $\mathrm{r}=0.87, \mathrm{p}=0.0009$; osteonal $\mathrm{r}=0.87, \mathrm{p}=0.002$; endosteal $\mathrm{r}=0.75, \mathrm{p}=0.02$ ), unlike the OVX ones. 


\section{References}

[1] S. Khosla, L.J. Melton, 3rd, B.L. Riggs, The unitary model for estrogen deficiency and the pathogenesis of osteoporosis: is a revision needed?, J Bone Miner Res 26(3) (2011) 44151.

[2] S. Khosla, M.J. Oursler, D.G. Monroe, Estrogen and the skeleton, Trends Endocrinol Metab 23(11) (2012) 576-81.

[3] S. Khosla, S. Amin, E. Orwoll, Osteoporosis in men, Endocr Rev 29(4) (2008) 441-64.

[4] A.M. Parfitt, Recent developments in bone physiology, Henry Ford Hosp Med J 31(4) (1983) 209-10.

[5] E.P. Paschalis, S. Gamsjaeger, N. Hassler, K. Klaushofer, D. Burr, Ovarian hormone depletion affects cortical bone quality differently on different skeletal envelopes, Bone 95 (2017) 55-64.

[6] P. Garnero, E. Sornay-Rendu, M.C. Chapuy, P.D. Delmas, Increased bone turnover in late postmenopausal women is a major determinant of osteoporosis, J Bone Miner Res 11(3) (1996) 337-49.

[7] A. Tomkinson, J. Reeve, R.W. Shaw, B.S. Noble, The death of osteocytes via apoptosis accompanies estrogen withdrawal in human bone, J Clin Endocrinol Metab 82(9) (1997) $3128-35$

[8] K.B. Emerton, B. Hu, A.A. Woo, A. Sinofsky, C. Hernandez, R.J. Majeska, K.J. Jepsen, M.B. Schaffler, Osteocyte apoptosis and control of bone resorption following ovariectomy in mice, Bone 46(3) (2010) 577-83.

[9] A. Tomkinson, E.F. Gevers, J.M. Wit, J. Reeve, B.S. Noble, The role of estrogen in the control of rat osteocyte apoptosis, J Bone Miner Res 13(8) (1998) 1243-50. 
[10] U.I. Modder, J.A. Clowes, K. Hoey, J.M. Peterson, L. McCready, M.J. Oursler, B.L. Riggs, S. Khosla, Regulation of circulating sclerostin levels by sex steroids in women and in men, J Bone Miner Res 26(1) (2011) 27-34.

[11] F. Callewaert, M. Sinnesael, E. Gielen, S. Boonen, D. Vanderschueren, Skeletal sexual dimorphism: relative contribution of sex steroids, GH-IGF1, and mechanical loading, $\mathbf{J}$ Endocrinol 207(2) (2010) 127-34.

[12] M.R. Allen, J.M. Hock, D.B. Burr, Periosteum: biology, regulation, and response to osteoporosis therapies, Bone 35(5) (2004) 1003-12.

[13] E. Bonucci, P. Ballanti, Osteoporosis-bone remodeling and animal models, Toxicol Pathol 42(6) (2014) 957-69.

[14] C. Turner, D. Burr, J. Hock, Brommage, M. Sato, The effects of PTH (1-34) on bone structure and strength in ovariectomized monkeys., in: S. Majumdar, B. Bay (Eds.), Noninvasive Assessment of Trabecular Bone Arfchitecture and the Competence of Bone. , Academic/Plenum Publishers, New York, 2001, pp. 496:165-179.

[15] M. Kasra, M.D. Grynpas, Effect of long-term ovariectomy on bone mechanical properties in young female cynomolgus monkeys, Bone 15(5) (1994) 557-61.

[16] D.B. Burr, T. Hirano, C.H. Turner, C. Hotchkiss, R. Brommage, J.M. Hock, Intermittently administered human parathyroid hormone(1-34) treatment increases intracortical bone turnover and porosity without reducing bone strength in the humerus of ovariectomized cynomolgus monkeys, J Bone Miner Res 16(1) (2001) 157-65.

[17] E.P. Paschalis, S. Gamsjaeger, N. Fratzl-Zelman, P. Roschger, A. Masic, W. Brozek, N. Hassler, F.H. Glorieux, F. Rauch, K. Klaushofer, P. Fratzl, Evidence for a Role for Nanoporosity and Pyridinoline Content in Human Mild Osteogenesis Imperfecta, J Bone Miner Res 31(5) (2016) 1050-9. 
[18] G.S. Mandair, M.D. Morris, Contributions of Raman spectroscopy to the understanding of bone strength, Bonekey Rep 4 (2015) 620.

[19] S. Gamsjaeger, K. Klaushofer, E. Paschalis, Raman analysis of proteoglycans simultaneously in bone and cartilage. , Journal of Raman Spectroscopy 45(9) (2014) 794-800. [20] S. Gamsjaeger, W. Brozek, R. Recker, K. Klaushofer, E.P. Paschalis, Transmenopausal changes in trabecular bone quality, J Bone Miner Res 29(3) (2014) 608-17.

[21] E.P. Paschalis, P. Fratzl, S. Gamsjaeger, N. Hassler, W. Brozek, E.F. Eriksen, F. Rauch, F.H. Glorieux, E. Shane, D. Dempster, A. Cohen, R. Recker, K. Klaushofer, Aging Versus Postmenopausal Osteoporosis: Bone Composition and Maturation Kinetics at ActivelyForming Trabecular Surfaces of Female Subjects Aged 1 to 84 Years, J Bone Miner Res 31(2) (2016) 347-57.

[22] E.P. Paschalis, S. Gamsjaeger, K. Klaushofer, Vibrational spectroscopic techniques to assess bone quality, Osteoporos Int 28(8) (2017) 2275-2291.

[23] S. Gamsjaeger, R. Mendelsohn, A.L. Boskey, S. Gourion-Arsiquaud, K. Klaushofer, E.P. Paschalis, Vibrational spectroscopic imaging for the evaluation of matrix and mineral chemistry, Curr Osteoporos Rep 12(4) (2014) 454-64.

[24] A.J. Smith, S.K. Singhrao, G.R. Newman, R.J. Waddington, G. Embery, A biochemical and immuno-electron microscopical analysis of chondroitin sulphate-rich proteoglycans in human alveolar bone, Histochem J 29(1) (1997) 1-9.

[25] A.L. Boskey, L. Spevak, S.B. Doty, L. Rosenberg, Effects of bone CS-proteoglycans, DS-decorin, and DS-biglycan on hydroxyapatite formation in a gelatin gel, Calcif Tissue Int 61(4) (1997) 298-305.

[26] Y. Mochida, D. Parisuthiman, S. Pornprasertsuk-Damrongsri, P. Atsawasuwan, M. Sricholpech, A.L. Boskey, M. Yamauchi, Decorin modulates collagen matrix assembly and mineralization, Matrix Biol 28(1) (2009) 44-52. 
[27] K.L. Nielsen, M.R. Allen, S.A. Bloomfield, T.L. Andersen, X.D. Chen, H.S. Poulsen, M.F. Young, A.M. Heegaard, Biglycan deficiency interferes with ovariectomy-induced bone loss, J Bone Miner Res 18(12) (2003) 2152-8.

[28] Y.M. Sauren, R.H. Mieremet, C.G. Groot, J.P. Scherft, An electron microscopic study on the presence of proteoglycans in the mineralized matrix of rat and human compact lamellar bone, Anat Rec 232(1) (1992) 36-44.

[29] W.R. Thompson, S. Modla, B.J. Grindel, K.J. Czymmek, C.B. Kirn-Safran, L. Wang, R.L. Duncan, M.C. Farach-Carson, Perlecan/Hspg2 deficiency alters the pericellular space of the lacunocanalicular system surrounding osteocytic processes in cortical bone, J Bone Miner Res 26(3) (2011) 618-29.

[30] Y. Mochida, W.R. Duarte, H. Tanzawa, E.P. Paschalis, M. Yamauchi, Decorin modulates matrix mineralization in vitro, Biochem Biophys Res Commun 305(1) (2003) 6-9. [31] A.L. Boskey, M. Maresca, A.L. Armstrong, M.G. Ehrlich, Treatment of proteoglycan aggregates with physeal enzymes reduces their ability to inhibit hydroxyapatite proliferation in a gelatin gel, J Orthop Res 10(3) (1992) 313-9.

[32] S.P. Robins, Biochemistry and functional significance of collagen cross-linking, Biochem Soc Trans 35(Pt 5) (2007) 849-52.

[33] M. Yamauchi, Collagen: The major matrix molecule in mineralized tissues., in: J.J.B. Anderson, S.C. Garner (Eds.), Calcium and Phosphorus in Health and Disease, CRC Press, New York, 1996, pp. 127-141.

[34] H. Oxlund, M. Barckman, G. Ortoft, T.T. Andreassen, Reduced concentrations of collagen cross-links are associated with reduced strength of bone, Bone 17(4 Suppl) (1995) 365S-371S. 
[35] H. Oxlund, L. Mosekilde, G. Ortoff, Alterations in the stability of collagen from human trabecular bone with respect to age., in: C. Christiansen, J.S. Johansen, B.J. Riis (Eds.), Osteoporosis 1987, Osteopress APS, Copenhagen, 1987, pp. 309-312.

[36] E.P. Paschalis, D.N. Tatakis, S. Robins, P. Fratzl, I. Manjubala, R. Zoehrer, S. Gamsjaeger, B. Buchinger, A. Roschger, R. Phipps, A.L. Boskey, E. Dall'ara, P. Varga, P. Zysset, K. Klaushofer, P. Roschger, Lathyrism-induced alterations in collagen cross-links influence the mechanical properties of bone material without affecting the mineral, Bone 49 (2011) 1232-41.

[37] E.M. McNerny, B. Gong, M.D. Morris, D.H. Kohn, Bone fracture toughness and strength correlate with collagen cross-link maturity in a dose-controlled lathyrism mouse model, J Bone Miner Res 30(3) (2015) 455-64.

[38] M.H. Wassen, J. Lammens, J.M. Tekoppele, R.J. Sakkers, Z. Liu, A.J. Verbout, R.A. Bank, Collagen structure regulates fibril mineralization in osteogenesis as revealed by crosslink patterns in calcifying callus, J Bone Miner Res 15(9) (2000) 1776-85. 


\section{Highlights}

i. Earliest deposited mineral content decreases with osteoid glycosaminoglycan content and increases with osteoid pyridinoline content in SHAM operated monkeys.

ii. There are no significant correlations between earliest deposited mineral content and osteoid glycosaminoglycan and pyridinoline content in ovariectomized monkeys.

iii. These results suggest that estrogen depletion alters the mineralization regulation 
(a)

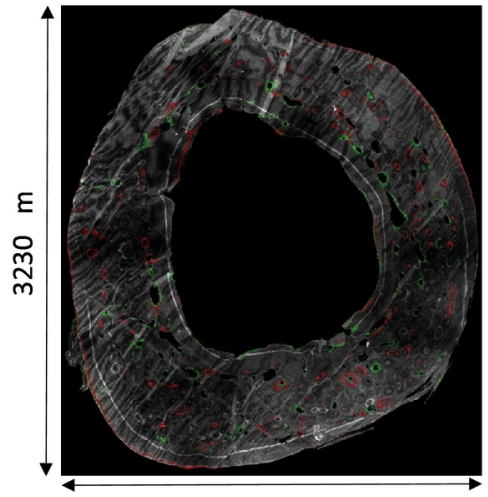

\section{$2260 \mathrm{~m}$}

(b)
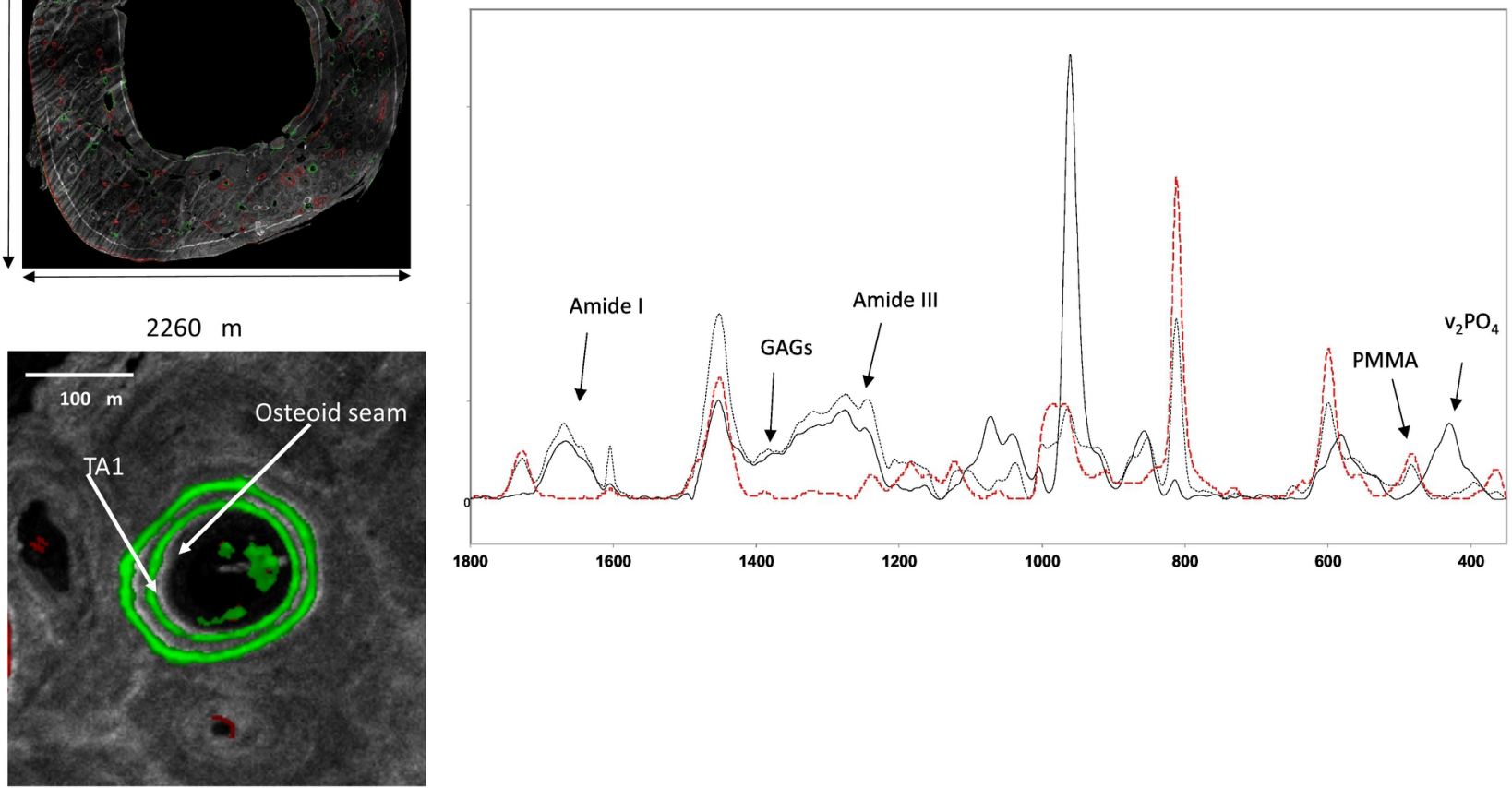

Figure 1 
Periosteal

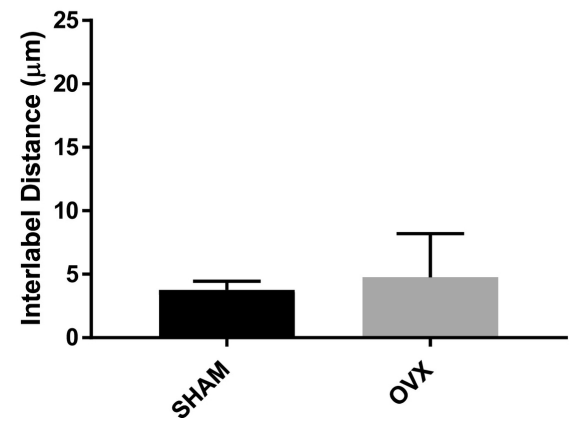

Osteons

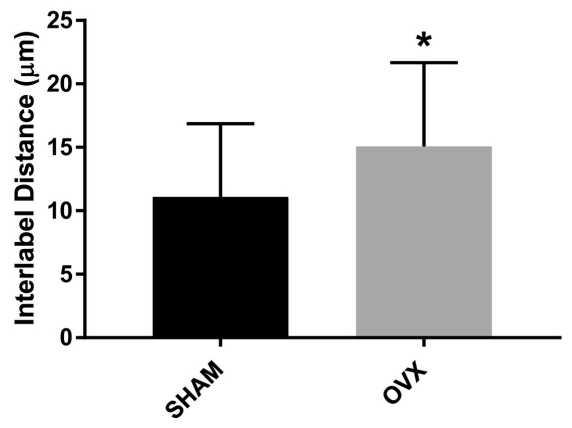

Endosteal

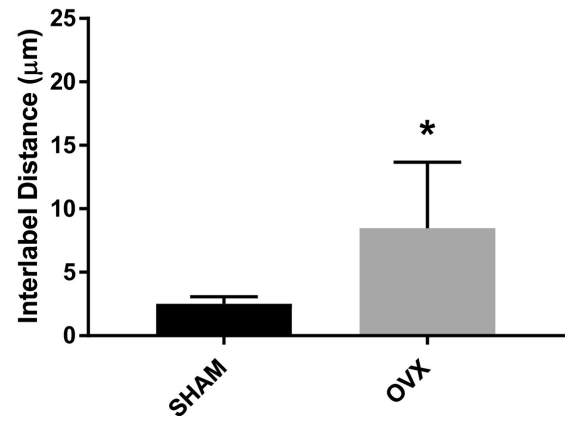

Figure 2 
Periosteal

Osteoid
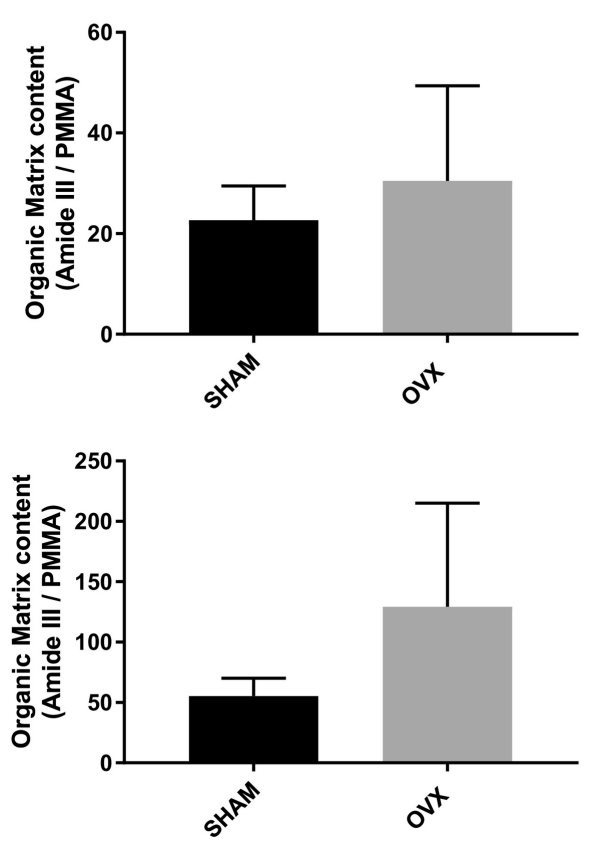

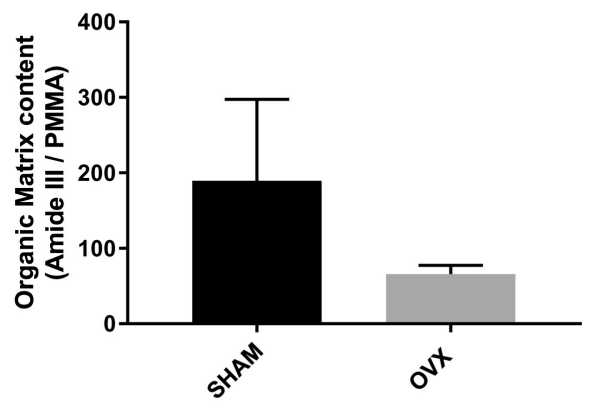

Osteons

Endosteal

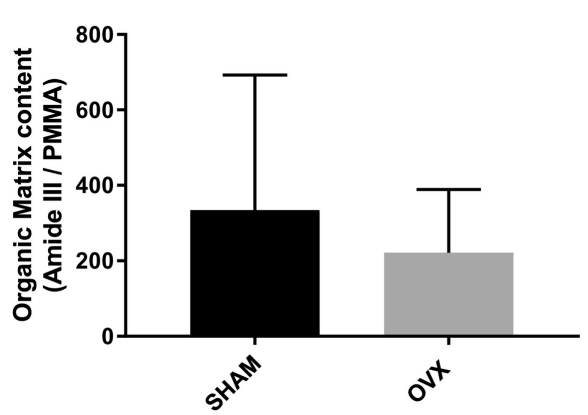

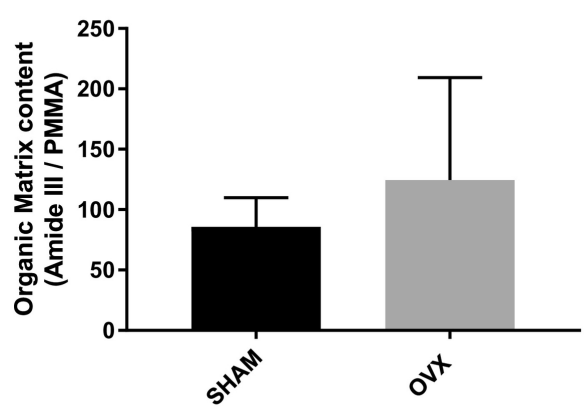

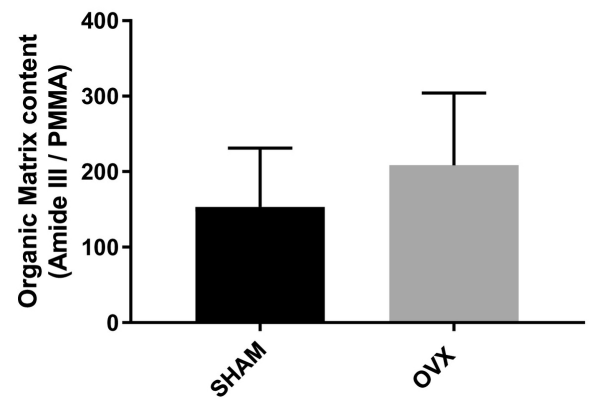

Figure 3 
Periosteal
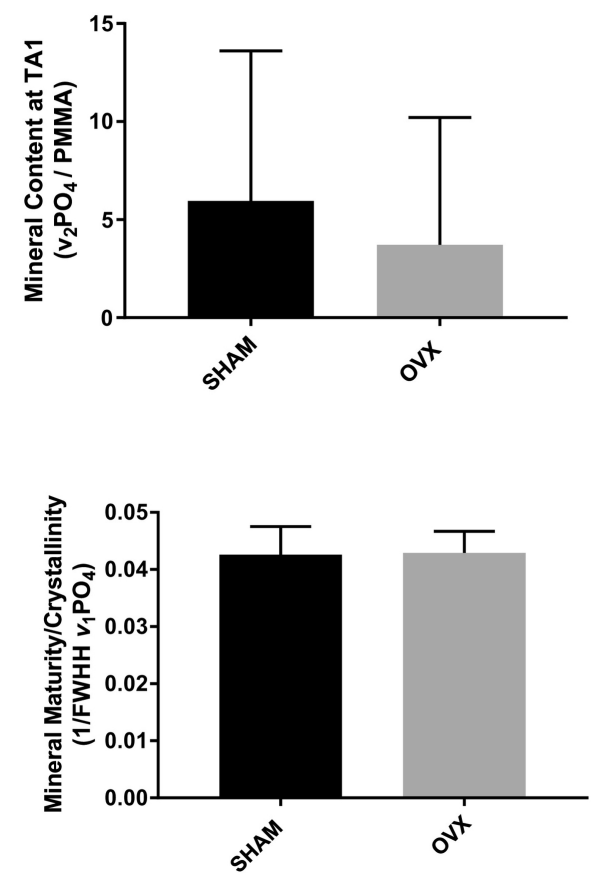

Osteons
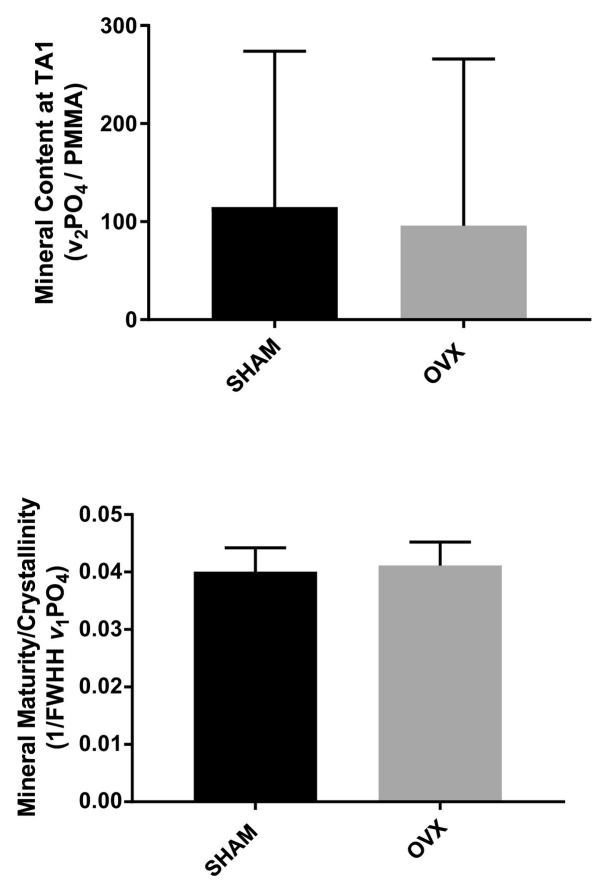

Endosteal
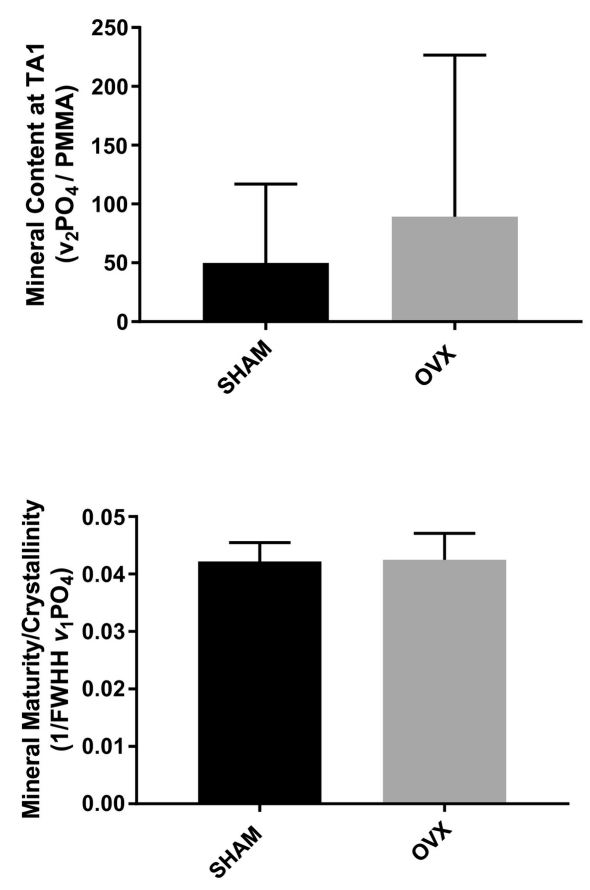
Periosteal
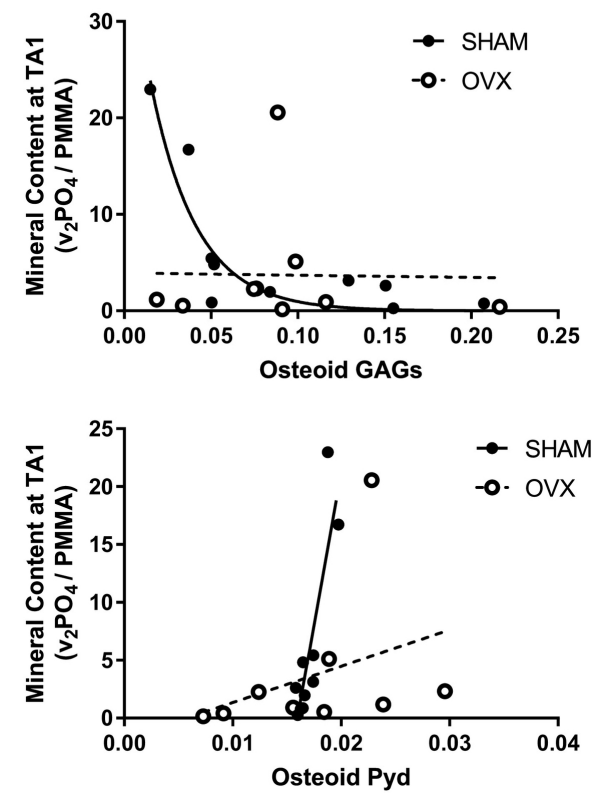

Osteons
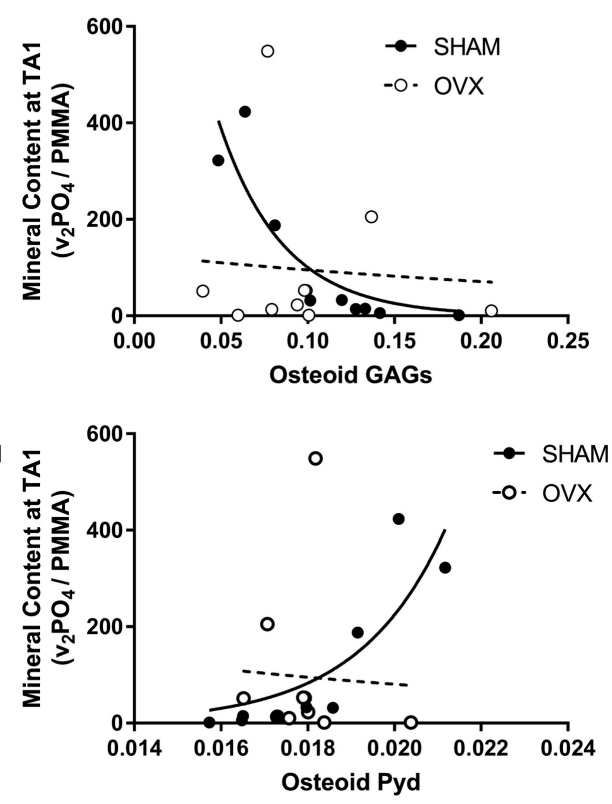

Endosteal
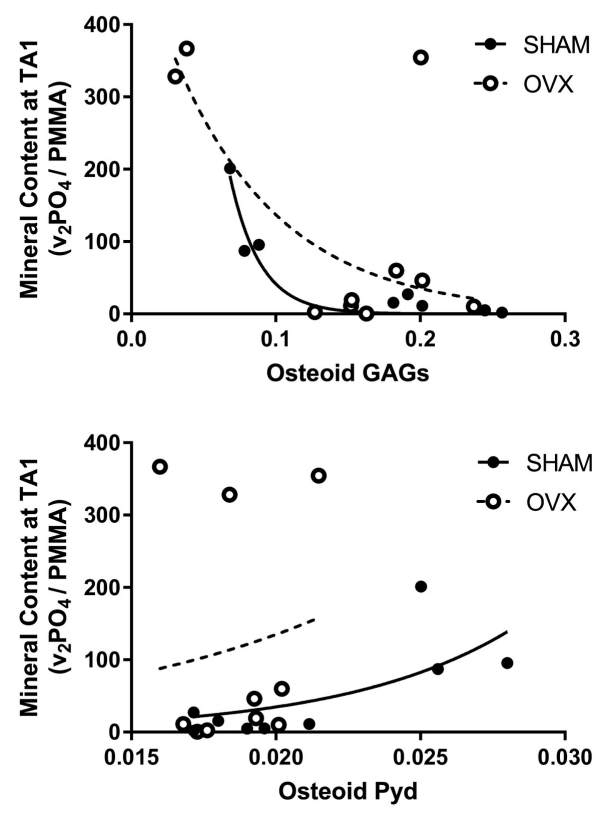